\title{
Rural-Urban Migration, Childbearing Decision- Making, Fertility and Contraceptive Perspectives of Street Adolescents and Youth in Kampala, Uganda
}

Mulekya Francis Bwambale ( $\nabla$ francisbmf@gmail.com )

Maastricht University CAPHRI https://orcid.org/0000-0003-3559-4868

Cheryl A Moyer

University of Michigan Medical School

Paul Bukuluki

Makerere University College of Humanities and Social Sciences

Bart van den Borne

Maastricht University Faculty of Health, Medicine and Life Sciences: Maastricht Universitair Medisch Centrum+

\section{Research}

Keywords: rural-urban migration, childbearing decision-making, contraceptive and fertility intentions, Uganda.

Posted Date: August 24th, 2021

DOl: https://doi.org/10.21203/rs.3.rs-796808/v1

License: (c) (1) This work is licensed under a Creative Commons Attribution 4.0 International License. Read Full License 


\section{Abstract \\ Background}

This paper aimed at describing childbearing decision-making, fertility and contraceptive intentions and associated social demographic factors among disadvantaged street adolescents and youth in Kampala, Uganda while considering rural-urban migration aspects as an explanatory factor.

\section{Methods}

A cross-sectional survey of 513 adolescents and youth aged 12-24 years self-identifying as street adolescents and youth were interviewed with a structured questionnaire in 2019. Street adolescents and youth who migrated from other rural districts to Kampala were compared with those from the city. Street adolescents and youth who migrated from other rural districts to Kampala were classified as migrants while those without the rural experience were considered non-migrants. Logistic regression was applied to assess associations between independent factors and personal childbearing decision-making, fertility intentions and contraceptive intentions.

\section{Results}

Overall, $80.31 \%$ of the street adolescents and youth had a rural-urban migration experience. Fifty six percent (56.32\%) of the street adolescents and youth made personal childbearing decisions, $94.15 \%$ expressed intentions to have children in the future and $42.88 \%$ expressed intentions to use contraceptives in the future. Intentions to use contraceptives were significantly higher among males (58.75\%) than females (20\%). Contraceptive intentions were positively associated with self-perceived permanent residential status $(\mathrm{aOR}=10.26,2.70-39.08)$, more intra-urban mobility $(\mathrm{aOR}=4.99,95 \% \mathrm{Cl} 1.50-16.59)$ and intentions to migrate to other towns within the country $(\mathrm{aOR}=5.33,95 \% \mathrm{Cl} 1.59-17.80)$. Regarding migration aspects, street adolescents and youth who had cyclic movements between the city and district of origin were less likely to make personal childbearing decisions compared to those who never had repeat migration $(\mathrm{aOR}=0.23,95 \% \mathrm{Cl} 0.05-0.94)$. We found no significant association between the social demographic characteristics and fertility intentions.

\section{Conclusions}

Street adolescents and youth with a rural-urban migration experience have less control over personal childbearing decision-making and contraceptive intentions than the non-cyclic migrant counterparts. Factors that influence personal childbearing decision-making and contraceptive intentions among street adolescents and young people in Kampala city operate mainly at the interpersonal and local level, with migration and mobility patterns playing a central role in both perspectives. Programmes and services to 
prevent promote contraceptives and contraceptive use particularly among the vulnerable street adolescents and youth should take into consideration migration patterns of the street children.

\section{Plain English Summary}

The subject of rural-urban migration and reasons that influence childbearing decision-making, contraceptive and fertility intentions among urban street adolescents and youth is not well understood. In this study, the research team sought to establish the reasons including the influence rural-urban migration on personal childbearing decision-making, contraceptive desires as well as desires to have children among street youth aged 12 to 24 years in Kampala, Uganda. The study involved conducting interviews with sample of 513 street adolescents and youth at locations and streets of Kampala capital city where they congregate during daytime. Street adolescents and youth who migrated from other rural districts to Kampala were compared with those from the city. We apply statistical tests to determine the reasons that are associated with personal childbearing decision-making, fertility intentions and contraceptive intentions.

The study findings show that the majority (80.31\%) of the street adolescents and youth living in Kampala had migrated from rural districts. The study further revealed that 9 in 10 street adolescents and youth expressed intentions to have children in the future, more than half of them made personal childbearing decisions while $42.88 \%$ expressed intentions to use contraceptives in the future. The desire to use contraceptives in the future was higher among males (58.75\%) than females (20\%). Street youth who perceived themselves to have stable residence in city, had lived in more than one space/location in the city since migration, and those with intentions to move to another town had increased desire to use contraceptives in the future. On the other hand, street adolescents and youth who had repeated movements between the city and district of origin within the last 24 months prior to the survey were less likely to make personal childbearing decisions compared to those who never had repeat migration ( $\mathrm{aOR}=$ $0.23,95 \% \mathrm{Cl} 0.05-0.94)$. the study team did not find any correlation between age, sex and marital status with and fertility intentions.

In conclusion, the desire to use contraceptives in the future is generally low among street adolescents and youth. Reasons influencing personal childbearing decision-making and contraceptive intentions among street adolescents and youth include mainly migration, intra-city mobility and stable residence within the city. The study team recommends that programmes to promote contraceptives and reduce tenable pregnancy among street adolescents and youth should take into consideration migration patterns of the street children.

\section{Key words}

rural-urban migration, childbearing decision-making, contraceptive and fertility intentions, Uganda.

\section{Background}


Over the past decades, the influence of internal migration on family formation patterns, both partnerships and childbearing, has interested social scientists(1)(2)(3). Migration can be conceptualised as a process of fundamental life changes. Psychological distress and hardships, but also benefits and opportunities, created by settling into new environments may influence fertility and partnering behaviours(4)(5). Social networks are found to be more important factors driving migration intentions than work-related aspects while stronger close social networks at home have the opposite effect by reducing the likelihood of migration intentions, both internationally and locally(6). However, the influence of internal migration on reproductive health has received less attention in the literature.

Available literature further suggests that migration may induce a change in how individuals make decisions about important events such as when and whether to have a child(7). Decline in fertility has been reported among migrants after settling in the urban areas and may be due in part to temporary spousal separation(8). Concerns about fertility are prevalent among youth and might predict low contraception uptake (7). Women and men with lower earnings, less education, and more worries about their future job prospects are more uncertain whether they will have children(9). Similarly, children of teenage parents face poorer infant health, and a greater probability of becoming teen parents themselves.

Uganda still exhibits high rates of unintended teenage pregnancies, high maternal mortality ratio of 336 per 100,000 live births and neonatal mortality rate of 27/1000 live births(10). Studies based on data from demographic and health surveys show that while fertility has remained at pre-transition level in Uganda over the past 20 years, there are signs of decline in fertility with specific groups of women especially the most educated and those in urban settings(11). Although fertility rates in Uganda have decreased considerably in the last decades-the number of children per women of childbearing age decreased from 6.9 in 2000 to 5.4 in 2016, adolescent fertility rates have declined much more slowly(12).

While $25 \%$ of women age 15-19 have begun childbearing, modern contraceptive use among married and sexually active unmarried adolescents is generally low at $9.4 \%(13)(14)$. The persistent low contraceptive use coupled with the high teenage pregnancy rate is attributed to sexual practices, limited access to contraception, perceptions and inadequate knowledge on contraceptives and fear of side effects(15). Our previous work showed that low utilisation of modern contraceptives with $30.68 \%$ of the non-migrant street adolescents and youth having used a modern family planning method compared to $17.73 \%$ of established migrants and $14.44 \%$ of new migrants(16). Among refugee adolescents, the desire to become pregnant in refugee settlements in northern Uganda is low at $7.0 \%(17)$.

Youth mobility continues to characterize Uganda's rural-urban migration patterns with a population shift from rural to urbanised areas. Most of the migrants are youth aged 15-35 years(18). Previous models have attempted to identify the influence of significant others, including partners, peers, and family; and sociodemographic factors including age, ethnicity, marital status, education, and income as predictors of contraceptive use and gender considerations in contraceptive decision-making(19). Communication ability with husbands and family members appear to influence contraception use and consequently result in early childbearing among married adolescent girls(20). Marital status remains a strong predictor for 
number of children born (21). However, literature that examines urban street adolescents and youth's fertility motivations, childbearing choices, and future use of contraceptives in the context of rural-urban migration is limited in Uganda and sub-Saharan Africa.

This study attempts to fill the above gap by examining the social demographic factors associated with childbearing decision-making, contraceptive and fertility intentions among urban street adolescents and youth in Kampala, Uganda. Also, we interrogate the influence migration may have on personal childbearing decision-making and contraceptive and fertility intentions. We hypothesise that street adolescents and youth's childbearing decision-making, contraceptive and fertility intentions will vary by migration, age, and sex. We focus on the street adolescents and youth because of the global call to ensure universal sexual and reproductive health $(\mathrm{SRH})$ coverage and improve urban health for all without leaving no one behind - especially vulnerable youth. Adolescent childbearing and contraceptive perspectives are considered critical to teenage pregnancies and hence achieving the Sustainable Development Goals (SDG) target three on universal SRH coverage (22).

In Uganda, adolescent sexual and reproductive health is recognised as a priority intervention area in national policy guidelines(23). Understanding childbearing decision-making and fertility intentions can be a powerful predictor of women's contraceptive behaviour and therefore may have substantial policy implications in framing future family planning strategies to improve the sexual and reproductive health of urban street adolescents and youth, who are often disregarded in the urban policy and plans (24). In addition, knowledge of the migration intentions of street adolescents and youth is important in predicting future actual migration and its impact on future fertility rates. In this current work, we conceptualize fertility intentions as the desire to have children in the future, irrespective of duration while childbearing decision-making is defined as ability of the street adolescent and youth to make own decisions regarding the number of children to have. Contraceptive intentions are conceptualised as the desire to use contraceptives in the future.

\section{Methods}

This study uses data from a cross-sectional survey of 513 street adolescents and youth aged 12-24 years in Kampala, Uganda conducted between April and July 2019. Detailed methods have been described in our previous work (16)(25), but will be briefly reviewed in this section. The study was conducted in three of five divisions of the Kampala capital city, and these include Makindye, Rubaga and Central divisions. Eligible participants included adolescents and youth aged 12 to 24 years who identified themselves as street adolescents and youth. To select the sampling units (parishes) for the interviews, we applied proportionate allocation sampling based on the street-youth population size estimates and number of geographic locations/venues in which street adolescents and youth congregate during daytime. Within each congregation venue, venue-based time-space (VBTS) sampling technique was applied to select eligible participants(25). All interviews were conducted in private spaces on the streets by a team of 14 trained research assistants. Access to the street adolescents and youth was made possible through their peer social networks, caregivers and local urban leaders who served as guides 
during data collection. In compensation for their participation in the study, street adolescents and youth were rewarded with an incentive of United States dollar (USD) 0.6. All interviews were conducted on the streets and in areas where street children congregate during daytime using a pre-tested semi-structured questionnaire that was translated into the local languages, Luganda and Ngakaramajong, which are commonly spoken by the street-youth and configured on Tablet computers. This was aimed to minimise non-response and improve the internal validity of the responses.

\section{Measurements}

Childbearing decision-making was assessed by asking the question: Who makes decisions for you regarding the number of children you want/would like to have in the future? (Responses: self, partner, my partner and me, parents/In-laws, friends/peers, other). A street youth was considered to have made personal childbearing decision-making if he or she made the decision alone. Fertility intentions were assessed by asking the question: Are you planning/hoping to have any children in the future? Yes/No. Contraceptive intentions were measured by asking the question: Do you have any plans to use any modern family planning method in the future? Yes/No. A "Yes" response to the two questions above was considered as expressed fertility intentions and contraceptive intentions, respectively.

\section{Data analysis}

Statistical analysis was conducted in Stata (version 15). At analysis, participants with a rural-urban experience were classified as migrants while those without the rural urban experience were considered as non-migrants. Other aspects of migration measured includes repeat movements between the city and districts of origin. as well as intra-urban mobility, defined as the number of moves or places stayed in since migrating to the city. Descriptive characteristics of participants are presented as frequencies and percentages. For bivariate analyses, crosstabulations were applied to study associations with childbearing decision-making, contraceptive and fertility intentions by migration status and sex.

Associations were tested using Pearson Chi-Square $\left(x^{2}\right)$ tests. Statistical significance was obtained using $95 \%$ confidence interval $(\mathrm{Cl})$ at $p<0.05$. Multivariate logistic regression analyses were conducted on the three binary outcomes of interest (childbearing decision-making, fertility, and contraceptive intentions). All factors significant at the p-value of 0.05 at the bivariate analysis including migration status and known predictors of the three study outcomes were entered into the final binary logistic regression models as shown in Tables 2, 3 and 4. 
Table 1

Crosstabulation of socio-demographics, childbearing decision-making, fertility and contraceptive intentions among street dolescents and youth by sex and migration status, Kampala, Uganda, 2019.

\begin{tabular}{|c|c|c|c|c|c|c|}
\hline Characteristic & $\begin{array}{l}\text { Male } \\
\mathrm{n}(\%)\end{array}$ & $\begin{array}{l}\text { Female } \\
\text { n (\%) }\end{array}$ & $\begin{array}{l}x^{2} \\
\text { (p/t- } \\
\text { test) }\end{array}$ & $\begin{array}{l}\text { Non- } \\
\text { migrant } \\
\text { n (\%) }\end{array}$ & $\begin{array}{l}\text { Migrant } \\
\text { n (\%) }\end{array}$ & $\begin{array}{l}x^{2} \\
\text { (p/t- } \\
\text { test) }\end{array}$ \\
\hline \multirow{2}{*}{$\begin{array}{l}\text { Age (in complete } \\
\text { years) }\end{array}$} & & & 0.12 & & & 1.01 \\
\hline & & & $(0.736)$ & & & $(0.312)$ \\
\hline $12-17$ & $117(38.61)$ & 78(37.14) & & $34(33.66)$ & 161(39.08) & \\
\hline $18-24$ & 186(61.39) & $132(62.86)$ & & $67(66.34)$ & $251(60.92)$ & \\
\hline Mean age (SD) & $15.22(1.53)$ & $20.44(2.02)$ & & $19.04(3.23)$ & $18.31(3.09)$ & \\
\hline \multirow[t]{2}{*}{ Marital status } & & & 105.82 & & & 12.578 \\
\hline & & & $\begin{array}{l}(< \\
0.001)\end{array}$ & & & $\begin{array}{l}(< \\
0.001)\end{array}$ \\
\hline Not married & 295(97.36) & $132(62.86)$ & & $96(95.05)$ & $331(80.34)$ & \\
\hline Married/cohabiting & $8(2.64)$ & $78(37.14)$ & & $5(4.95)$ & $81(19.66)$ & \\
\hline \multirow{2}{*}{$\begin{array}{l}\text { Childbearing } \\
\text { decision-making }\end{array}$} & & & 62.85 & & & 8.32 \\
\hline & & & $\begin{array}{l}(< \\
0.001)\end{array}$ & & & $(0.004)$ \\
\hline Other & $82(28.77)$ & $129(65.15)$ & & $29(30.53)$ & $182(46.91)$ & \\
\hline Self & 203(71.23) & $69(34.85)$ & & $66(69.47)$ & 206(53.09) & \\
\hline \multirow[t]{2}{*}{ Fertility intentions } & & & 0.01 & & & 0.00 \\
\hline & & & $(0.914)$ & & & $(0.965)$ \\
\hline No & $18(5.94)$ & $12(5.71)$ & & $6(5.94)$ & $24(5.83)$ & \\
\hline Yes & 285(94.06) & 198(94.29) & & $95(94.06)$ & $388(94.17)$ & \\
\hline \multirow{2}{*}{$\begin{array}{l}\text { Contraceptive } \\
\text { intentions }\end{array}$} & & & 76.02 & & & 50.54 \\
\hline & & & $\begin{array}{l}(< \\
0.001)\end{array}$ & & & $\begin{array}{l}(< \\
0.001)\end{array}$ \\
\hline No & $125(41.25)$ & $168(80.00)$ & & $26(25.74)$ & $267(64.81)$ & \\
\hline Yes & 178(58.75) & $42(20.00)$ & & $75(74.26)$ & 145(35.19) & \\
\hline $\begin{array}{l}\text { Median sexual } \\
\text { debut (IQR) }\end{array}$ & $16(8-21$ & $17(12-20)$ & & $16(10-20)$ & $17(7-21)$ & \\
\hline $\mathrm{cOR}=$ Crude Odds $\mathrm{R}$ & ; $\mathrm{aOR}=\mathrm{Adju}$ & d Odds Ratio & & & & \\
\hline
\end{tabular}


Table 2

Model 1 - Binary logistic regression of migration aspects and social demographic factors with childbearing decision-making among street adolescents and youth in Kampala, Uganda, 2019.

\begin{tabular}{|c|c|c|}
\hline Explanatory factors & $\begin{array}{l}\text { Bivariate model } \\
\text { cOR }(95 \% \mathrm{Cl})\end{array}$ & $\begin{array}{l}\text { Multivariate model } \\
\text { aOR }(95 \% \mathrm{Cl})\end{array}$ \\
\hline Age in years $(<17 \mathrm{yrs}=0,18$ and above $=1)$ & $0.81(0.56-1.18)$ & $0.79(0.228-2.719)$ \\
\hline Sex $($ male $=0$, female $=1)$ & $0.22(0.15-0.32)$ & $0.63(0.130-2.917)$ \\
\hline Education attained (primary $=0$, secondary + tertiary $=1$ ) & $1.86(1.19-2.90)$ & $2.60(0.750-9.00)$ \\
\hline Marital status (not married $=0$, married $=1$ ) & $0.22(0.13-0.37)$ & $0.13(0.02-0.85)$ \\
\hline Mean shelter occupants $(<=$ mean $=0,>$ mean $=1)$ & $0.42(0.28-0.66)$ & $0.13(0.03-0.63)$ \\
\hline Religion (other $=0$, Christian $=1$ ) & $0.60(0.38-0.95)$ & $0.73(0.18-2.88)$ \\
\hline Residential status $($ Mobile $=0$, permanent $=1$ ) & $2.82(1.91-4.17)$ & $0.546(0.13-2.36)$ \\
\hline Sex debut $(<18 y r r s, 18$ years $\&$ above $=1)$ & $0.43(0.26-0.71)$ & $2.824(0.66-12.07)$ \\
\hline Intra-urban mobility (non-mover $=0$, mover $=1$ ) & $2.36(1.58-3.54)$ & $0.74(0.22-2.47)$ \\
\hline Circular migrant (no $=0$, yes $=1$ ) & $0.46(0.30-0.72)$ & $0.23(0.05-0.94)$ \\
\hline Experienced challenges during migration ( $\mathrm{no}=0$, yes $=1$ ) & $0.30(0.19-0.47)$ & $0.20(0.05-0.72)$ \\
\hline Intention to migrate to another town $(\mathrm{no}=0$, yes $=1$ ) & $2.09(1.42-3.08)$ & $0.53(0.15-1.82)$ \\
\hline Belongs to a support group (no $=0$, yes $=1$ ) & $1.24(0.76-2.04)$ & $4.66(1.30-16.63)$ \\
\hline Source of social support $($ Other $=0$, friends $=1$ ). & $0.64(0.45-0.92)$ & $0.66(0.24-1.87)$ \\
\hline Migration status (non-migrant $=0$, migrant $=1$ ) & $0.50(0.31-0.80)$ & $0.29(0.01-6.71)$ \\
\hline
\end{tabular}


Table 3

Model 2 - Binary logistic regression of migration aspects and social demographic factors with contraceptive intentions among Street adolescents and youth in Kampala, Uganda, 2019.

\begin{tabular}{|c|c|c|}
\hline Explanatory variables & $\begin{array}{l}\text { Bivariate model } \\
\text { cOR }(95 \% \mathrm{Cl})\end{array}$ & $\begin{array}{l}\text { Multivariate model } \\
\text { aOR }(95 \% \mathrm{Cl})\end{array}$ \\
\hline Age in years $(<18$ years $=0,18$ and above $=1)$ & $1.17(0.82-1.68)$ & $1.14(0.27-4.84)$ \\
\hline Sex $($ male $=0$, female $=1)$ & $0.18(0.12-0.26)$ & $0.331(0.05-2.06)$ \\
\hline Education attained (primary $=0$, secondary + tertiary $=1$ ) & $3.28(2.14-5.04)$ & $0.926(0.27-3.22)$ \\
\hline Marital status (not married $=0$, married $=1$ ) & $0.27(0.16-0.48)$ & $4.130(0.50-34.31)$ \\
\hline Mean shelter occupants $(<=$ mean $=0,>$ mean $=1)$ & $0.24(0.15-0.40)$ & $0.300(0.06-1.52)$ \\
\hline Religion (other $=0$, Christian $=1$ ) & $0.27(0.17-0.42)$ & $0.483(0.11-2.09)$ \\
\hline Residential status (Mobile $=0$, permanence $=1$ ) & $8.54(5.70-12.80)$ & $10.264(2.70-39.08)$ \\
\hline Sex debut $(<18$ years $=0,18$ years $\&$ above $=1)$ & $0.48(0.29-0.80)$ & $2.291(0.54-9.75)$ \\
\hline Intra-urban mobility (non-mover $=0$, mover $=1$ ) & $4.58(2.93-7.17)$ & $5.00(1.50-16.59)$ \\
\hline Circular migrant (no $=0$, yes $=1$ ) & $0.28(0.17(0.48)$ & $0.99(0.25-3.94)$ \\
\hline Experienced challenges during migration (no $=0$, yes $=1$ ) & $0.68(0.45-1.05)$ & $0.85(0.25-2.91)$ \\
\hline Intention to migrate to another town(yes = 1 ) & $5.72(3.84-8.51)$ & $5.33(1.59-17.80)$ \\
\hline Belongs to a support group (no $=0$, yes $=1$ ) & $2.56(1.59-4.12)$ & $1.32(0.37-4.77)$ \\
\hline Source of social support (Other $=0$, friends $=1$ ) & $0.57(0.40-0.81)$ & $0.73(0.27-2.21)$ \\
\hline Migration status $($ non-migrant $=0$, migrant $=1$ ) & $0.19(0.12-0.31)$ & $4.33(0.23-80.48)$ \\
\hline $\mathrm{cOR}=$ Crude Odds Ratio; $\mathrm{aOR}=$ Adjusted Odds $\mathrm{F}$ & & \\
\hline
\end{tabular}


Table 4

Model 3 - Binary logistic regression of migration aspects and social demographic factors with fertility intentions among Street adolescents and youth in Kampala, Uganda, 2019.

\begin{tabular}{|c|c|c|}
\hline Explanatory factors & $\operatorname{cOR}(95 \% \mathrm{Cl})$ & aOR $(95 \% \mathrm{Cl})$ \\
\hline Age in years $(18$ and above $=1)$ & $2.24(1.06-4.72)$ & $0.19(0.01-4.44)$ \\
\hline Sex $($ male $=0$, female $=1)$ & $1.04(0.49-2.21)$ & $0.06(0.00-2.01)$ \\
\hline Education attained (primary $=0$, secondary + tertiary $=1$ ) & $1.32(0.54-3.21)$ & $0.08(0.00-2.0)$ \\
\hline Marital status (not married $=0$, married $=1$ ) & $0.79(0.32-2.00)$ & $1.50(0.15-15.10)$ \\
\hline Mean household occupants $(<=$ mean $=0,>$ mean $=1)$ & $0.44(0.21-0.97)$ & $0.06(0.00-1.33)$ \\
\hline Religion (other $=0$, Christian $=1$ ) & $2.55(1.19-5.48)$ & $0.562(0.03-12.38)$ \\
\hline Residential status $($ mobile $=0$, permanence $=1$ ) & $0.83(0.40-1.76)$ & $2.28(0.20-24.13)$ \\
\hline Sex debut $(18$ years $\&$ above $=1)$ & $1.42(0.38-5.38)$ & $18.13(0.59-559.24)$ \\
\hline Intra-urban mobility $($ non-mover $=0$, mover $=1$ ) & $0.93(0.41-2.10)$ & $0.34(0.03-4.38)$ \\
\hline Circular migrant (no $=0$, yes $=1$ ) & $3.06(0.90-10.45)$ & $32.53(0.71-1501.21)$ \\
\hline Experienced challenges during migration (no $=0$, yes $=1$ ) & $0.66(0.29-1.51)$ & $0.20(0.02-2.05)$ \\
\hline Intention to migrate to another town(yes $=1$ ) & $1.33(0.56-3.11)$ & 7.443(0.52-106.81) \\
\hline Belongs to a support group (yes $=1$ ) & $0.54(0.23-1.25)$ & $1.736(0.16-18.80)$ \\
\hline Peer $/$ social support $($ Other $=0$, friends $=1)$. & $1.13(0.54-2.38)$ & $1.787(0.23-13.70)$ \\
\hline Migration status (non-migrant $=0$, migrant $=1$ ) & $1.02(0.41-2.57)$ & 1.000 \\
\hline $\mathrm{cOR}=$ Crude Odds Ratio; $\mathrm{aOR}=$ Adjusted Odds Ratio & & \\
\hline
\end{tabular}

\section{Ethical considerations}

Both caregiver/guardian consent and informed assent were obtained for respondents 17 years and younger, guided by the Uganda National Council of Science and Technology (UNSCT) guidelines on conducting research with human subjects(26). Written informed consent and assent were obtained prior to the interview.

\section{Results}

\section{Background characteristics:}

The total sample size was 513 street adolescents and youth: 303 males (59.06\%) and 210 females (40.94\%). The mean age was 18.46 years (SD 3.14) and varied significantly for females (20.44 years) and males (15 years). The median sexual debut was 17 years, 16 years for females and 17 years for males. More than a third of the females $(37.14 \%)$ compared to males $(2.64 \%)$ were in conjugal relations. Approximately $16.76 \%(n=86)$ of the street adolescents and youth were in conjugal relationships. 
Regarding living arrangements, $12.09 \%$ of the street adolescents and youth stayed alone, $57.31 \%$ stayed with a partner or friend, $10.9 \%$ stayed with parents (both parents, mother, and father alone) while 19.69\% stayed with siblings/relatives. Irrespective of age, the mean number of children per street adolescent and youth was two children $(\overline{\mathrm{x}}=1.67$, SD 0.83$)$ for females and one child $(\overline{\mathrm{x}}=1.24, \mathrm{SD} 0.44)$ for males, and the range was $1-4$ children.

Regarding migration status, $80.31 \%$ of the street adolescents and youth had migrated to the city while $19.69 \%$ of the street adolescents and youth were non-migrants. Circular migration, defined as having more than one repeat migration between Kampala capital city and district of origin was found to be frequent. Almost half (51.76\%) of migrant street adolescents and youth had more than one repeat migration to the district of origin in the past 24 months prior to the survey, with a median of two (2) repeat migrations $(\mathrm{IQR}=7(\mathrm{Q} 1-\mathrm{Q}=1, \mathrm{Q} 3=8)$ ). About three quarters $(71.06 \%)$ of the street adolescents and youth had intentions to return to their districts of origin; $45.22 \%$ desired to relocate to another space within the city while $34.70 \%$ desired to migrate to another urban centre within the country.

\section{Childbearing decision-making}

About half (56.32\%) of the street adolescents and youth expressed making own personal childbearing decisions, (28.57\%) made joint decisions with a sexual partner and $15.11 \%$ involved other people parents, friends, in-laws, and God, in childbearing decision making. Most non-migrants (69.47\%) made personal childbearing decision making compared to their migrant counterparts $(53.09 \%)(\chi 2=7.8870 ; a=$ 0.005). Less than three-quarters $(71.23 \%)$ of the male street adolescents and youth made personal childbearing decisions compared to $34.85 \%$ of their female counterparts. About three quarters $(77.18 \%)$ of non-circular migrants and $22.82 \%$ of circular migrants expressed personal childbearing decisionsmaking, respectively. To establish if street adolescents and youth and their sexual partners' childbearing preferences were in agreement, participants were asked if they wanted the same number of children, more or fewer than their sexual partners. Overall, $15.11 \%(n=73)$ of the street adolescents and youth wanted the same number of children as their partners, $8.70 \%(n=42)$ wished to have more children, $12.42 \%(n=$ 60) desired fewer children while $63.77 \%$ were undecided on the number of children.

\section{Fertility Intentions}

First, we asked if both male and female street adolescents and youth had ever had any children in their lifetime. Overall, $64.06 \%$ of the females compared to $13.09 \%$ of the males reported having had children in their lifetime while 33.54\% ( $n=107$ ) had ever become pregnant (for females) or impregnated (for males). At the time of the survey, $8.10 \%(n=17)$ of the female street adolescents and youth were pregnant. Among those who were pregnant, $88.24 \%(n=15)$ were in conjugal relations and $82.35 \%(n=14)$ were aged 18 years or older. Second, we assessed fertility intentions among street adolescents and youth by asking them about their plans to have children in the future. Overall, $94.15 \%$ of the street adolescents and youth expressed intentions to have children in the future, irrespective of duration. Among the females, $84.76 \%(n=178)$ affirmed their desire to have children in the future, $1.43(n=3)$ had intentions to become 
pregnant now, $8.10 \%(n=17)$ were currently pregnant while $5.71 \%(n=12)$ reported no firm intentions to have children in the future.

\section{Contraceptive intentions}

We assessed both contraceptive use and intentions to use contraceptives among street adolescents and youth. Of the 513 respondents, less than half $(42.88 \%)$ of the street adolescents and youth expressed intentions to use contraceptives in the future. About two thirds $(65.91 \%)$ of migrants and $34.09 \%$ of nonmigrants experienced expressed contraceptive intentions, respectively. Of the 412 migrant street adolescents and youth, $14.48 \%$ of circular migrants expressed desire to have children in the future compared to $85.52 \%$ of non-circular migrants. Contraceptive use was low with $18.13 \%$ of the street adolescents and youth having used modern contraceptives. The most preferred contraceptive was a condom $(75 \%)$ followed by an injectable $(11.36 \%)$, intra uterine device $(8.64 \%)$, oral contraceptive (3.64\%) and Norplant (1.36\%).

\section{Factors Associated With The Three Outcomes}

\section{Childbearing decision-making}

Table 2 shows the results of the bivariate and multivariate models with childbearing decision-making as the primary outcome. The odds of personal childbearing decision making were $87 \%$ lower if street adolescents and youth were in conjugal relation compared to those in non-conjugal relations $(\mathrm{aOR}=0.13$, $95 \% \mathrm{Cl} 0.02-0.85$ ). Similarly, the odds of personal childbearing decision making were $87 \%$ lower if the mean number of street adolescents and youth living in a shelter was more than five occupants compared to those with fewer shelter occupants $(\mathrm{aOR}=0.13,95 \% \mathrm{Cl} 0.03-0.63)$. The odds of personal childbearing decision-making were $50 \%$ lower if the street adolescent and youth were migrants compared to the nonmigrants ( $\mathrm{COR}=0.50,95 \% \mathrm{Cl} 0.31-0.81$ ). In fact, circular migrants were $52 \%$ less likely to make own childbearing decisions compared to non-circular migrants $(\mathrm{cOR}=0.46,95 \% \mathrm{Cl} 0.30-0.72)$. Migrant street adolescents and youth were $50 \%$ less likely to make own childbearing decisions than their non-migrant counterparts ( $\mathrm{cOR}=0.50,95 \% \mathrm{Cl} 0.31-0.81)$. In this study sample, the proportion of migrants was $80.31 \%$ $(n=412)$ of which circular migrants constituted $29.37 \%(n=121)$.

After controlling for cofounding, a few variables, that is, marital status, mean shelter population size, circular migration aspects and belonging to a support group remained statistically significant in the final model. Street adolescents and youth who were in conjugal relationships were $87 \%$ less likely to make own decisions regarding childbearing than the non-married $(\mathrm{aOR}=0.13,95 \% \mathrm{Cl} 0.12-0.85)$. Similarly, the odds of personal childbearing decision-making were reduced if street adolescents and youth size was more than a mean population size of five occupants compared to those staying in shelters with fewer people $(\mathrm{aOR}=0.13,95 \% \mathrm{Cl} 0.03-0.63)$. The odds of personal childbearing decision-making were $74 \%$ lower if the street adolescents and youth had repeated movements in the past 24 months prior to the survey compared to non-repeat movers $(\mathrm{aOR}=0.25,95 \% \mathrm{Cl} 0.07-0.968)$. Similarly, the odds of personal childbearing decision-making were reduced by $80 \%$ if street adolescents and youth experienced 
challenges during the migration process compared to those who did not experience any challenge $(\mathrm{aOR}=$ $0.20,95 \% \mathrm{Cl} 0.55-0.72)$. Belonging to a social support group increased the likelihood of personal childbearing decision-making by four-fold among street adolescents and youth compared to those who had no belonging to a social support group $(\mathrm{aOR}=4.25 ; 95 \% \mathrm{Cl} 1.21-14.96)$. Notably, age and sex did not remain significant in the adjusted model.

\section{Contraceptive Intentions}

Table 3 shows the results of the bivariate and multivariate models with contraceptive intentions as the primary outcome. The desire for future contraceptive use was associated with the intention to migration intentions. Street adolescents and youth with intentions to migrate to another town within the country were 5.72 times more likely to have future contraceptive desires ( $\mathrm{COR}=5.51,95 \% \mathrm{Cl} 3.84-8.41)$. A similar finding was observed for those wanting to migrate to another country (cOR 5.51,95\% $\mathrm{Cl} 3.77-8.08$ ). The odds of contraceptive intentions increased by six-fold for the street adolescents and youth who had intentions to migrate outside the country than those who did not want to migrate $(\mathrm{cOR}=6.25,95 \% \mathrm{Cl}$ 4.12-9.50). The odds of contraceptive intentions were $0.61 \%$ lower among circular migrant street youth in circular rural-urban movement than non-circular migrants $(\mathrm{COR}=0.29,95 \% \mathrm{Cl} 0.17-0.48)$. Intentions to use contraceptives varied significantly by migration status with non-migrants being 7.73 times more likely to express desire to use contraceptives in the future compared to the migrants $(O R=7.34,95 \% \mathrm{Cl}$ 4.17-12.91). Similarly, migrants were $90 \%$ less likely to express desire for use of contraceptive in the future $(\mathrm{cOR}=0.19,95 \% \mathrm{Cl} 0.12-0.31)$.

In the final logistic regression model, contraceptive intentions were positively associated with selfperceived permanent residential status, intra-urban mobility, and intentions to migrate. Street adolescents and youth who considered themselves to be permanently residents of the city were 10.26 times more likely to express intentions for contraceptive use than those who perceived themselves to be mobile residents (aOR $=10.26,2.700-39.08)$. Intra-urban mobility, defined as having moved or stayed in more than one place/location since migrating to the city, increased the likelihood of contraceptive intentions by five-hold among movers compared to non-movers ( $\mathrm{aOR}=4.99,95 \% \mathrm{Cl} 1.50-16.59)$. Similarly, street children with intentions to migrate to other towns within the country were 5.33 times more likely to likely to express contraceptive intentions than those without migration intentions $(\mathrm{aOR}=5.33,95 \% \mathrm{Cl} 1.59$ 17.80).

\section{Fertility Intentions}

Table 4 shows the results of the bivariate and multivariate models with fertility intentions as the primary outcome. Street adolescents and youth's fertility intentions were associated with being married (cOR = $3.47,95 \% \mathrm{Cl} 2.11-5.71), 18$ years or older $(\mathrm{COR}=2.87,95 \% \mathrm{Cl} 1.88-4.37)$, having attained primary or secondary ( $\mathrm{cOR}=1.95,95 \% \mathrm{Cl} 1.27-2.98)$, earning a daily income of $>1 \mathrm{USD}(\mathrm{cOR}=1.67,95 \% \mathrm{Cl} 1.07-2.61)$ and belonging to a support group $(\mathrm{COR}=2.04,95 \% \mathrm{Cl} 1.26-3.33)$. The odds of fertility intentions were $54 \%$ lower if the street adolescents and youth had first sex in life before age 18 than the adult street youth $(\mathrm{cOR}=0.46,95 \% \mathrm{Cl} 0.28-0.77)$. 


\section{Migration Status As A Predictor Of The Three Outcomes}

As shown in Tables 2, 3 and 4, migration status was associated with personal childbearing decisionmaking, contraceptive intentions, and fertility intentions at the bivariate analysis. After controlling for confounding, the relationship between childbearing decision-making and rural-urban circular migration and challenges associated with the migration process remained statistically significant. That is, the odds of personal childbearing decision-making were $77 \%$ lower if the street adolescent and youth had circular migrations compared to their non-circular migrant counterparts. Street adolescents and youth who experienced challenges during the migration process were $80 \%$ less likely to make personal childbearing decisions $(\mathrm{aOR}=0.20,95 \% \mathrm{Cl} 0.05-0.72)$. Moreover, street adolescents and youth with increased intraurban mobility were five times more likely to express desires to have children in the future than the less mobile street youth $(\mathrm{aOR}=5.33,95 \% \mathrm{Cl} 1.59-17.80)$. Similarly, street adolescents and youth with intentions to migrate to other urban centres in Uganda were five times more likely to express contraceptive intentions than those without intentions to migrate $(\mathrm{aOR}=5.33,95 \% \mathrm{Cl} 1.59-17.80)$. No significant association between fertility intentions and migration status was found in the final model.

\section{Discussion}

The present paper focuses on describing and assessing socio-demographic factors associated with childbearing decision-making, fertility intentions, and contraceptive intentions as the three main study outcomes among urban street adolescents and youth aged 12-24 in Kampala, Uganda. We tested whether the migration status and mobility have an influence on the three study outcomes (childbearing decision making, contractive and fertility intentions) using logistic regression. Contraceptive intentions were positively associated with intra-urban mobility, intentions to migrate to other towns within the country and self-perceived permanent residence in the capital city. Childbearing decision-making was associated with circular migration, being married, mean shelter population size more than five people and belonging to a social support group. No significant differences were observed between fertility intentions and socio-demographic factors.

In our study, intentions to use contraceptives were significantly higher among males (58.75\%) than females $(20 \%)$ which seems to be consistent with the generally low contraceptive use in Uganda as demonstrated by national demographic and health survey findings(27). The low contraceptive intentions may signify more male empowerment over females and an increased susceptibility of female street adolescents to unwanted pregnancies. On the other hand, the observed negative relationship of intraurban mobility and intentions to migrate with the desire to use contraceptives in the future imply that internal migration and mobility could potentially inhibit current and future use of contraceptives among this vulnerable group of urban street adolescents and youth. A previous study in Pakistan confirms the linkage between local human mobility and intention to use contraceptives among married young women aged 15-24 years (20). Similarly, our study findings showed that contraceptives intentions were positively associated with self-perceived permanent residence in the city which suggests that residential 
stability in the city may increase access to or awareness of family planning services among street youth who consider themselves as permanent residents of the city.

The relationship of marital status and belonging to a social support network with personal childbearing decision-making suggests that inter-personal and informal social interactions may play an important role in building consensus over childbearing decision-making. It is possible that street adolescents and youth in conjugal relationships could be particularly susceptible to relationship of peer social influence regarding their childbearing decision-making processes. In fact, further exploration of our data shows a significant association between marital status and peer social support ( $p$-value $=0.8$ ). It is possible that street adolescents and youth in conjugal relationships are likely to make joint decisions regarding childbearing decision-making as opposed to individualised decisions. Elsewhere, spousal communication on reproductive matters has been found to influence family planning couple joint decision-making(28).

The inverse relationship between mean shelter population size and personal childbearing decisionmaking suggests that the bigger the shelter population size, the less likely for street adolescents and youth to make personal decisions regarding childbearing. This finding could be explained by the poor housing or living conditions of the street adolescents and youth in the city spaces. Within the local context, the sharing of temporary shelters among street adolescents and youth, which are often crowded, may deprive them of confidential sexual activity and not offer them flexibility to decide on having children. Further interrogation of our data revealed high correlation between big shelter population above the mean with non-condom use at last sex and having sex with multiple sexual partners in the last 12 months ( $p$-value > > 0.001). In Europe, small youth dwellings for youth students have been criticized for not facilitating family formation and fertility. On the other hand, affordable housing is not enough to promote childbearing, instead, it seems to inhibit childbearing until there is a possibility of moving on to better housing(29). A previous study conducted in the USA confirm shelter-related childbearing obstacles among married homeless women who felt uncomfortable to have a baby or become pregnant in overcrowded family shelters, citing that it would be traumatic, insecure and stressful to bear children in such an environment(30). However, with the risky sexual behaviours and practices, including early sexual debut, multiple sexual partners or unprotected sex, reported among street adolescents and youth in urban slums of Kampala(25)(28), personal decisions about avoiding pregnancy may be inevitable.

Circular migration, defined as having more than one repeat migration between Kampala capital city and district of origin was inversely associated with personal childbearing decision-making. This finding denotes that because of the uncertainty of where they would move next, street adolescents and youth may be worried about having children as their cyclic migration journeys may be challenging. Second, this could also mean that they are highly mobile because they have not met their aspirations of rural-urban migration within the urbanised setting, and they would perhaps not want to start bearing children until they have stable incomes. In this study, street adolescents and youth who earned one USD or more daily were twice likely to make own personal childbearing decisions ( $p$-value $=0.001$ ). The reduced odds of childbearing decision-making among cyclic migrant street adolescents and youth compared to their noncircular counterparts may further denote spousal, parental or family influence on their childbearing 
decision-making processes. In our study sample, very few street adolescents and youth stayed with their parents, spouses, or family members in the city, which naturally may compel them to periodically travel to their districts to interact with the partners or families left behind. These can influence their childbearing decision making. Parental guidance may play a positive supportive role in helping slum youth living in Kampala capacity city to shape their behaviour, positively solve problems, deal with survival and other traumatic experience(28).

Relatedly, street adolescents and youth who experienced a problem or challenges during the migration process were less likely to make personal decisions regarding childbearing. Some of the risks or challenges associated with the migration process are well documented and include frequent cooccurrence of sexual risks such as sexual violence with physical, emotional and socio-economic forms of violence and sexual assault (31)(32)(33). While the reason for this finding may be unclear, it is possible that a person who has gone through an unpleasant situation such as sexual health risks during the migration process may find it difficult to make personal childbearing decisions as having childbearing may be perceived as an additional burden.

Notably, we found no significant relationship between fertility intentions and social demographic factors which is in contrast with previous studies conducted within the international migration contexts, which fertility intentions as a function of age, educational level, and marital status. The variation in findings with our study could be attributed to the difference in migration contexts, life expectancy and socioeconomic contexts of the two countries/regions. However, irrespective of childbearing age, $94 \%$ of the street adolescents and youth expressed desire of having children in the future. In Uganda, intentions to have children are consistently high including even among people living with HIV with $88.2 \%$ wanting to have children in the future(34). However, given high youth unemployment and declining fertility rates in the country, positive fertility intentions may tend to be over-optimistic and may or may not necessarily be realised in the future(35).

\section{Study Limitations}

This study had some limitations. We did not aim to explore variations in childbearing choices and contraceptive intentions based on reason for migration. Thus, those who migrated for education, employment or marriage may have differences in their intentions to have future children. However, given that most of the street adolescents and youth in our study sample were not in school and not so schooled, with majority having attended primary education, their reasons for rural-urban migration are unlikely to have affected the findings. A previous study shows that young peoples' views on motivation for childbearing in Uganda are embedded in cultural norms and linked strongly to patriarchy, social respectability, and women's sustenance(36). This study did not assess for other factors such as cultural beliefs, social norms and values which may have an influence on street adolescents and youth's childbearing decision-making, fertility, and contractive perspectives. Since the study was limited to studying street adolescents and youth living in Kampala capital city, it was not possible to assess household characteristics of their families left behind which may have an influence on their fertility and 
contraceptive intentions. Our previous work demonstrated lack of significant association between contraceptive use and migration status (16) and hence, we did not find it worth investigating its association in this study. However, our study demonstrates a clear interrelation between childbearing decision-making and contraceptive intentions with migration and mobility among street adolescents and youth which is a novel finding. In view of limited evidence and literature on street youth's contraceptive intentions, this study provides the first empirical evidence on the influence of internal migration and mobility on childbearing decision-making and contraceptive intentions which in turn may predict actual contraceptive adoption by street adolescents and youth.

\section{Conclusions}

The main factors associated with personal childbearing decision-making and contraceptive intentions among street adolescents and youth in Kampala operate mainly at the interpersonal and local level, with migration and intra-urban mobility playing a central role in both perspectives. Our findings have implications in framing future adolescent and sexual and reproductive health policies and strategies for Kampala and other major cities in Uganda while taking into consideration rural-urban migration and intraurban mobility of street adolescents and youth. Contraceptive programmes to prevent pregnancy and decrease unmet need for family planning among the urban poor, especially the street adolescents and youth are highly recommended. Additional research is needed to examine the complex range of beliefs, norms and values which may influence street adolescents and youth's childbearing decision-making, contraceptive intentions, and realisation of fertility intentions. Moreover, a greater research to understand differences in these patterns between poor and non-poor in urban areas is needed to inform future program design.

\section{Abbreviations}

aOR - Adjusted Odds Ratio

cOR - Crude Odds Ratio

$\mathrm{Cl}$ - Confidence interval

IQR - Interquartile range

SRH - Sexual and reproductive health

\section{Declarations}

\section{Ethics approval and consent to participate}

The study protocol and all study materials were reviewed and approved by the Makerere University School of Social Sciences Research and Ethics Committee (Ref. MAKSS REC 12.18.389). 


\section{Consent for publication}

None

\section{Availability of data and materials}

The dataset analysed during the current study is available from the corresponding author on reasonable request.

\section{Competing interests}

None

\section{Funding}

This study was by the funded by the Care and Public Health Research Institute (CAPHRI) of the Maastricht University, Netherlands.

\section{Authors' contributions}

All authors contributed equally to the manuscript. All authors read and approved the final manuscript.

\section{Acknowledgements}

Special thanks go to the street adolescents and youth for their trust and participation in the study.

\section{References}

1. Goldberg D. The fertility of two-generation urbanites. Popul Stud (NY). 1959.

2. Kulu H. Migration and Fertility: Competing Hypotheses Re-examined. Eur J Popul / Rev Eur Démographie [Internet]. 2005;21(1):51-87. Available from: https://doi.org/10.1007/s10680-0053581-8.

3. Sobotka T. Overview Chap. 7: The rising importance of migrants for childbearing in Europe. Demographic Research. 2008.

4. Ritsner M, Ponizovsky A. Psychological Distress Through Immigration: the Two-Phase Temporal Pattern? Int J Soc Psychiatry [Internet]. 1999 Jun 1;45(2):125-39. Available from: https://doi.org/10.1177/002076409904500205.

5. Battaglia M. Migration, health knowledge and teenage fertility: evidence from Mexico. SERIEs [Internet]. 2015;6(2):179-206. Available from: https://doi.org/10.1007/s13209-015-0124-3.

6. Manchin M, Orazbayev S. Social networks and the intention to migrate. World Dev. 2018;109:36074.

7. UBOS-UDHS. Uganda Demographic and Health Survey. 2016. 
8. Brockerhoff M, Yang X. Impact of migration on fertility in sub-Saharan Africa. Soc Biol. 1994;41(12):19-43.

9. Brauner-Otto SR, Geist C. Uncertainty, Doubts, and Delays: Economic Circumstances and Childbearing Expectations Among Emerging Adults. J Fam Econ Issues [Internet]. 2018;39(1):88102. Available from: https://doi.org/10.1007/s10834-017-9548-1.

10. Uganda Bureau of Statistics (UBOS). Uganda bureau of statistics 2017 statistical abstract. Uganda Bureau of Statistics. Kampala; 2017.

11. Ezeh AC, Mberu BU, Emina JO. Stall in fertility decline in Eastern African countries: regional analysis of patterns, determinants and implications. Philos Trans R Soc B Biol Sci. 2009;364(1532):29913007.

12. Uganda Bureau of Statistics. GOVERNMENT OF UGANDA Uganda Demographic and Health Survey. 2016. Udhs 2016 [Internet]. 2016;625. Available from: www.DHSprogram.com.

13. Sserwanja Q, Musaba MW, Mukunya D. Prevalence and factors associated with modern contraceptives utilization among female adolescents in Uganda. BMC Womens Health [Internet]. 2021;21(1):61. Available from: https://doi.org/10.1186/s12905-021-01206-7.

14. Uganda Bureau of Statistics. Uganda Demographic and Health Survey 2016. Udhs 2016. 2016.

15. Blanc AK, Tsui AO, Croft TN, Trevitt JL. Patterns and trends in adolescents'contraceptive use and discontinuation in developing countries and comparisons with adult women. Int Fam Plan Perspect. 2009.

16. Bwambale MF, Bukuluki P, Moyer CA, Van den Borne BHW. Utilisation of sexual and reproductive health services among street children and young adults in Kampala, Uganda: does migration matter? BMC Health Serv Res [Internet]. 2021;21(1):169. Available from: https://doi.org/10.1186/s12913-02106173-1.

17. Bakesiima R, Cleeve A, Larsson E, Tumwine JK, Ndeezi G, Danielsson KG, et al. Modern contraceptive use among female refugee adolescents in northern Uganda: prevalence and associated factors. Reprod Health [Internet]. 2020;17(1):67. Available from: https://doi.org/10.1186/s12978-020-00921$y$.

18. Food and Agriculture Organization. Evidence on internal and international migration patterns in selected African countries. Knowl Mater [Internet]. 2017;1-12. Available from: http://www.fao.org/3/a-i7468e.pdf.

19. Sable MR, Libbus MK. Gender and contraception: A proposed conceptual model for research and practice. J Gender Cult Heal. 1998;3(2):67-83.

20. Hamid S, Stephenson R, Rubenson B. Marriage decision making, spousal communication, and reproductive health among married youth in Pakistan. Glob Health Action. 2011;4(1):5079.

21. Kabagenyi A, Reid A, Rutaremwa G, Atuyambe LM, Ntozi JPM. Has Uganda experienced any stalled fertility transitions? Reflecting on the last four decades (1973-2011). Fertil Res Pract [Internet]. 2015;1(1):14. Available from: https://doi.org/10.1186/s40738-015-0006-1. 
22. Fikree FF, Lane C, Simon C, Hainsworth G, MacDonald P. Making good on a call to expand method choice for young people - Turning rhetoric into reality for addressing Sustainable Development Goal Three. Reprod Health. 2017 Apr;14(1):53.

23. Ministry of Health Uganda. Adolescent Health Policy Guidelines and Service Standards [Internet]. Kampala; 2012. Available from: http://library.health.go.ug/publications/adolescenthealth/adolescent-health-policy-guidelines-and-service-standards.

24. KCCA. Strategic Plan 2014/15-2018/2019: Laying the foundation for Kampala city transformation. 2014.

25. Bwambale MF, Bukuluki P, Moyer CA, Borne BHW van den. Demographic and behavioural drivers of intra-urban mobility of migrant street children and youth in Kampala, Uganda. PLoS One. 2021;16(2):e0247156.

26. Uganda National Council for Science and Technology. National guidelines for research involving humans as research participants [Internet]. Kampala; 2014. Available from: http://mesau.mak.ac.ug/sites/default/files/Human Subjects Protection Guidelines July 2014_0.pdf.

27. Uganda Bureau of Statistics (UBOS). National Population and Housing Census 2014: Area Specific Profiles Kampala Capital City Authority. 2017.

28. Kasirye R, Mutaawe R. Sexual risks, Substance abuse and Protective factors among, Kampala Street and slum children. 2018.

29. Enström Öst C, Wilhelmsson M. Youth dwellings, higher education, and childbearing. KTH Royal Institute of Technology; 2015.

30. Kennedy S, Grewal MPHM, Roberts EM, Steinauer J, Dehlendorf C. A qualitative study of pregnancy intention and the use of contraception among homeless women with children. J Health Care Poor Underserved. 2014;25(2):757.

31. Keygnaert I, Dialmy A, Manço A, Keygnaert J, Vettenburg N, Roelens K, et al. Sexual violence and subSaharan migrants in Morocco: a community-based participatory assessment using respondent driven sampling. Global Health. 2014;10(1):1-16.

32. Marrujo R Women, Migration, and Sexual Violence. Hum rights along US-Mexico Bord Gendered violence insecurity. 2009;31.

33. Sznajder KK, Winchester MS, Biney AAE, Dodoo ND, Letsa D, Dodoo FN-A. The Migration Experience and Differential Risks to Sexual and Reproductive Health in Ghana. Heal Educ Behav [Internet]. 2020 Jul 8;47(5):718-27. Available from: https://doi.org/10.1177/1090198120939492.

34. Wagner GJ, Mindry D, Hurley EA, Beyeza-Kashesya J, Gwokyalya V, Finocchario-Kessler S, et al. Reproductive intentions and corresponding use of safer conception methods and contraception among Ugandan HIV clients in serodiscordant relationships. BMC Public Health. 2021;21(1):1-14.

35. Vidal S, Huinink J, Feldhaus M. Fertility intentions and residential relocations. Demography. 2017;54(4):1305-30.

36. Beyeza-Kashesya J, Neema S, Ekstrom AM, Kaharuza F. "Not a Boy, Not a Child": A qualitative study on young people's views on childbearing in Uganda. Afr J Reprod Health. 2010;14(1). 
Page 21/21 